\title{
QUE SON OS ETNONACIONALISMOS E OS CONFLITOS ÉTNICOS HOXE EN AMÉRICA LATINA?
}

\author{
Natividad Gutiérrez Chong
}

Universidad Nacional Autónoma de México 

Unha perspectiva global sobre o nacionalismo contemporáneo revela que en boa parte das rexións do mundo é posible identificar movementos nacionalistas que desafían o poder do Estado e as fronteiras territoriais desde dentro. A definición clásica do nacionalismo, de Kedourie, Hall ou Schopflin, como un «ideal de independencia» continúa vixente. $\mathrm{O}$ discurso nacionalista das organizacións vascas de España, os reclamos independentistas entre os movementos támiles de Sri Lanka ou a mobilización de chechenos en Rusia representan casos de nacionalismos de minorías que teñen como obxectivo separarse das estruturas estatais existentes. Esta mirada xeral ten, así e todo, unha notable excepción. América Latina é a única rexión do mundo onde a separación non está presente. Aínda que a etnicidade incrementou o seu significado político nos últimos anos coa aparición de movementos que enarboran intereses indíxenas, América Latina, ata esta centuria, non presenta movementos nacionalistas de minorías étnicas que demanden o seu propio Estado. Ben ao contrario, a visión política indíxena destacou pola súa participación en «repensar» a nación como un espazo pluricultural que recoñeza o conxunto de identidades colectivas tanto de indíxenas como de inmigrantes e que iso se canalice en propostas étnicas, nacionais ou transnacionais.

Nestas páxinas buscamos explicar a visión política dos pobos indíxenas, para o que cómpre precisar o marco teórico en que se encadra o conflito étnico que caracteriza a rexión estudada. Convén subliñar, desde agora, que por mor da frecuencia e multiplicidade de formas que distingue a numerosos casos de conflitos étnicos rexistrados non é posible abordar con suficiencia todos eles. Temos interese por identificar e distinguir as tendencias e manifestacións máis habituais, como veremos no seu momento.

A nosa proposta de análise, daquela, sitúa en primeiro lugar o contexto de Estados-nación e a caracterización dos nacionalismos vixentes. En tanto que a etnicidade resulta ser un eixe principal para a xestación e expresión de conflitos, 
trataremos de atopar, en segundo lugar, as variables estruturais que lle outorgan peso a este concepto. Por último, partimos de que o conflito étnico está inmerso no ámbito da política, de aí que a nosa proposta sexa a construción dun modelo de análise baseado no estudo dos conflitos étnicos ${ }^{1}$.

\section{ESTADOS-NACIÓN: DO NATION BUILDING AO MULTICULTURALISMO}

Co nation-building ao estilo latinoamericano e seguindo modelos e estratexias europeas, por exemplo, a educación masiva, os medios de comunicación e os rituais cívicos (Gellner, 1983; Hobsbawm, 1983), os Estados construíron as súas nacións. Non obstante, non se pretendía que un Estado liberal puidese satisfacer as demandas dos seus grupos culturais ou lingüísticos; tampouco xurdiron para responder á diversidade, ao contrario que sostiña Mallon. Por iso, os Estados-nación construídos a partir da segunda metade do século XX tentaron aparentar que eran homoxéneos, monoétnicos, monoculturais e que estaban claramente vinculados cunha etnia-nación dominante (Ibarra, 1992) e, xa que logo, en aberto antagonismo coa diversidade de toda índole, intolerante e ameazante, en constante atropelo e violación dos dereitos humanos e culturais. $\mathrm{Na}$ axenda do nation-building non había lugar nin conciencia polo respecto, nin a diversidade, a tolerancia ou a coexistencia. A fórmula para fabricar nacións baseábase en formar grandes comunidades cun idioma, lingua e identidade común, que puidesen ser gobernadas nun Estado unitario e cunha cultura e territorio comúns. Así era idealizada a nación moderna (Safran, 1995).

Os efectos deste concepto da modernidade, é dicir, a nación, derrubaron con máis forza os últimos redutos da etnicidade ${ }^{2}$. Para que existise a nación era pre-

\footnotetext{
${ }^{1}$ Esquema de Donald Horowitz e a Socioloxía do risco.

${ }^{2}$ É posible identificar varias escolas e achegas á etnicidade, entre as que destacan, os primordialistas, instrumentalistas e etnosimbolistas. O noso modelo de análise metodolóxica propón os enfoques complementarios, é dicir, unha soa tendencia é insuficiente para dar conta da profundidade e complexidade dos fenómenos. De aí que unha proposta para explicar o nacionalismo mexicano coa súa poderosa vertente étnica precisase construír un esquema de análise baseado en Ernst Gellner e Anthony D. Smith (Gutiérrez, 1999; Wade, 1997; Gabbert, 2006; Fenton, 2003; ou Esman, 2000).
} 
ciso que desaparecese a etnicidade, ou ben que se empregase selectivamente, como foi o caso do indixenismo mexicano. Polo tanto, a etnicidade, na era do nation building tivo unha dobre función; por unha banda, a súa asociación co pasado ancestral fai da etnicidade un compoñente xenuíno e lexítimo da identidade nacional, pero, por outra, a etnicidade na vida cotiá foi debilitada en moitos ángulos, desde a extinción e negación de linguas, ata a dificultade de que os indíxenas poidan localizar información sobre os núcleos de identidade, mitos de orixe e descendencia (Gutiérrez, 2006). Esta contradición da etnicidade explícase pola falta de condicións obxectivas ou da confianza necesaria para ser reproducida con liberdade ante a explícita hostilidade e discriminación da cultura dominante. Esta etnicidade, que semella ser mellor explicada en función da vixencia dun pasado que xa non é quen de reproducir ninguén, cobrou moita nostalxia entre a escola de científicos sociais e humanistas (Jenkins, 1999) que observaron e teorizaron con acento a desaparición e o desgaste da tradición polo pulo da modernidade e mais do consumo. A etnicidade, asociada de maneira ficticia ao pasado, diversa polas súas variacións lingüísticas e de prácticas culturais e, por iso, descoñecedora da lingua oficial e da cultura dominante, foi, como repetidamente sabemos, atribuída á pobreza, á marxinalidade e ao atraso. Sen dúbida, o Estado-nación causoulle danos e desgastes á etnicidade, quer porque a perseguiu, a ameazou ou quer porque a reduciu á pobreza, pero por iso tamén lle deu paso, nese espazo do nation-building, aínda sen predicilo, a un rexurdimento étnico de crecente vigor (Gutiérrez, 1999). Así pois, a nación moderna é obra do Estado, e como parte desta obra non había lugar para a diversidade nin comprensión ningunha coa etnicidade; non obstante, séculos despois, é nese espazo da modernidade do Estado-nación onde se está a construír unha nova etnicidade politizada.

\section{NACIÓN MULTICULTURAL OU ESTADO PLURINACIONAL: A AXENDA DO ACTIVISMO POLÍTICO INDÍXENA}

Para construír un Estado-nación de tipo homoxéneo foi vital a posta en marcha da educación en masa, o combate ao analfabetismo, o ensino da identidade nacional, é dicir, facer que o Estado chegase a todos os recunchos da patria terri- 
torial (Stavenhagen e Nolasco, 1988). Para construír esta homoxeneidade, unha das estratexias foi o indixenismo, sobre o que tantas páxinas se escribiron (Gamio, 1916; Aguirre Beltrán, 1952; Marroquín, 1972; Bartra, 1972). Baste dicir aquí que o indixenismo procurou a aculturación do "indio vivo»; deulle a educación básica, mesmo ata rudimentaria e moi incompleta, pero acercouno ás estruturas da modernidade noutros casos, para crear axentes de cambio entre os propios indíxenas; estendeu o seu proxecto educativo e logrou que indíxenas provenientes de contornos unicamente rurais recibiran educación do Estado (Gutiérrez, 1999). Ademais, acuñou unha nova categoría de profesores, os mestres rurais bilingües, que lle deron outro dinamismo á mobilidade social indíxena. Sobre esta nova categoría laboral xorde o entendemento de novos procesos relacionados coa visión política e a conciencia de identidade colectiva distinta, sobre os que se perfila o recoñecemento da nación diversa (Bonfil, 1979 e 1981; Fisher e Mckenna, 1996). Isto é: a asimilación non fixo desaparecer o indio, senón que lle deu as ferramentas para reformular, reconstruír ou reinventar a súa identidade negada (Gutiérrez, 1999). Con identidade diversa hai espazo para negociar o recoñecemento constitucional e a representación política, ámbitos que lles foron tamén negados ás etnicidades (Cossío, González, Roldán, 1988; Van Cott, 2000) ou ben non puideron ser aínda aproveitados polos pobos indios.

$\mathrm{O}$ maxisterio indíxena foi pioneiro no desmantelamento da homoxeneidade cultural e na apertura das variantes filosóficas e ideolóxicas arredor do recoñecemento das diversidades, por exemplo, o multiculturalismo ou pluralidade (Gutiérrez, 2002). Lembremos brevemente o impulso de organizacións transétnicas de gran peso político e capacidade de mobilización nos anos setenta. Pero tamén foi importante que desde as filas do maxisterio saísen dirixentes e intelectuais con conciencia étnica, sen os que sería imposible pensar na acción colectiva indíxena e, xa que logo, caracterizar conflitos motivados por intereses étnicos.

Agora ben, no corpo destes dirixentes e intelectuais indíxenas non só están hoxe os mestres, tamén os avogados, xornalistas, escritores, antropólogos e lingüistas, entre outros moitos. E coas ferramentas de información tecnolóxica e de estratexia política que toda elite politizada usa, andan na procura de formas para acceder ao Estado e así facer que as institucións burocráticas respondan e dean conta dos diversos intereses étnicos en tantos asuntos da axenda nacional. Así que, desde o espazo estrutural e simbólico que o nacionalismo de Estado 
propiciou, están a xurdir proxectos que poden transformar o Estado liberal, sen que iso signifique separación ningunha, como veremos máis adiante. Así pois, a acción colectiva indíxena está enmarcada na defensa dos seus intereses colectivos, xa sexan culturais, de patrimonio ou de recursos naturais. Tamén se manifesta esta acción colectiva en conflitos étnicos (Stavenhagen, 1996) que non se limitan só ao ámbito estatal, senón que tamén lles afectan aos proxectos transnacionais ou aos conflitos interétnicos.

É imposible xa definir o Estado-nación segundo o proxecto liberal que o fixo xurdir. Agora, o concepto está disgregado e apareceron moitas escolas de pensamento (Willett, 1998). Tanto a idea de nación multicultural como a de Estado plurinacional son usadas indistintamente. Isto é así porque varios Estados de América Latina (Colombia, México, Nicaragua, Ecuador ou Bolivia) lograron acordos que deron lugar a reformas constitucionais, multiculturalismo constitucional, que lles outorgan dereitos ás minorías étnicas, que, aínda que incompletos ou insuficientes, non tiñan precedente na historia de negación da diversidade do Estado liberal latinoamericano (Maybury 2002).

$\mathrm{Na}$ era democrática do multiculturalismo constitucional está presente a apertura á representación das minorías (Van Cott, 2000; Máiz e Requejo, 2005), o que se traduce en novas oportunidades por parte de actores políticos específicos, é dicir, partidos e organizacións políticas con cotas de identidade diferenciada, que demandan a súa inclusión e representación dentro das estruturas e institucións dun Estado. Por iso, sostemos que a axenda dun activismo político indíxena actual tende a buscar as oportunidades que lle permitan unha maior representación no Estado ao que histórica e territorialmente pertenceran.

\section{CONFLITIVIDADE ÉTNICA}

Que lugar ocupa América Latina no estudo dos nacionalismos e os conflitos étnicos? Ao comezo, dixemos que os fenómenos observables noutras partes do mundo, como os separatismos - nacionalismos- ou a violencia física a grande escala, entre unha nación dominante e unha ou máis etnias dominadas, non son factores recorrentes que caracterizan a rexión. Algúns fenómenos e características específicas da rexión engádenlles, así e todo, vixencia ao nacionalismo e á 
etnicidade en conflito, aínda que con algunhas complicacións conceptuais que nos parágrafos seguintes trataremos de dilucidar. A partir da vaga de recoñecementos do multiculturalismo constitucional na década dos noventa, comeza a crearse un terreo propicio para a renovación do instrumental metodolóxico do nacionalismo. Neste traballo, facemos referencia á análise de dúas dimensións que servirán de modelo conceptual para o estudo dos etnonacionalismos e os conflitos étnicos.

Coa chegada de Evo Morales á presidencia boliviana en 2007, algúns analistas de medios activaron o concepto de etnonacionalismo da seguinte forma. Trátase dun discurso de Estado incluínte da maioría indíxena, en aberta oposición ao imperialismo e ás forzas do mercado global, polo tanto, baseado nunha ideoloxía "posmarxista» que «explota o resentimento indíxena». Este temor por un rexurdimento andino céntrico foi expresado tamén co Movemento Indio Pachakutik, que procuraba construír as bases para o xurdimento dun Estado aimará que recuperase o territorio histórico arredor do lago Titicaca e que comprende os actuais estados de Perú, Chile e Bolivia ${ }^{3}$. Tanto o nacionalismo de Estado, aludindo á orixe etnohistórica das identidades aimará e quechua ${ }^{4}$ por un presidente que chegou ao poder por medios lexítimos, como o proxecto de fundación dun Estado supraterritorial con base étnica homoxénea son dúas novas versións do etnonacionalismo en América Latina. Ambas as dúas versións son, en opinión dos seus críticos e opositores, expresións de xenofobia e de «racismo invertido cara aos crioulos» ${ }^{5}$. Así e todo, aquí exploramos unha terceira versión: os procesos de loita dos pobos orixinarios que non buscan un Estado propio.

Resulta útil comezar a explicación que propoñemos co esquema de Donald Horowitz, en Ethnic Groups in Conflict, de 1985, porque o tratamento que lle dá á etnicidade -en África, Asia e no Caribe- mostra que é susceptible de múlti-

3 «El arribo del etnonacionalismo: Mapuches, un pueblo en marcha», Memoria viva, Chile, 5 de maio de 2005.

${ }^{4} \mathrm{O}$ uso do pasado étnico pola elite política para lexitimar un novo proxecto político non é un achado recente, máis ben observa en América Latina distintas e contrapostas tendencias desde a fin do século XIII. Desde o mexicanismo e o patriotismo crioulo, o eloxio ao pasado prehispánico, ata o rexeitamento de todo vestixio étnico orixinado no nacionalismo moderno do cono sur e o agora vixente «código moral dos incas».

${ }^{5}$ L. E. González Manrique: «El "etnonacionalismo": las nuevas tensiones interétnicas en América Latina», ARI, n. ${ }^{\circ}$ 59, Real Instituto Elcano, 2005. 
ples variacións e combinacións en contextos poscoloniais; ademais, este modelo comparativo, aínda vixente e que non foi superado por outro, permite tamén adaptalo aos casos emerxentes latinoamericanos:

- Grupos atrasados en rexións atrasadas.

- Grupos avanzados en rexións atrasadas.

- Grupos avanzados en rexións avanzadas.

- Grupos atrasados en rexións avanzadas ${ }^{6}$.

Os cualificativos de atrasado e avanzado son explicados por Horowitz en relación coa experiencia dos sistemas coloniais imperantes que crearon desigualdades económicas e unha división desigual do traballo que afondaron nas identidades étnicas. O cualificativo avanzado é para aqueles que se beneficiaron dun sistema educativo, dunha división de traballo non só confinada ás actividades primarias, da posición económica medida en termos de ingreso per capita, mentres que o de atrasado estaría determinado por un nivel educativo baixo, con menor capacidade de producir riqueza e que leva a carga dos prexuízos coloniais que son comúns sobre a suposta falta de disposición para o traballo e a aptitude empresarial dos nativos.

Para Horowitz, a primeira categoría é a que máis se beneficiaría cun Estado propio, pois son os máis discriminados e os que máis temen pola súa extinción. A segunda categoría non busca a separación, xa que con frecuencia estes se benefician de exportar a súa forza de traballo e capital a outro país. A terceira categoría tampouco quere a separación, porque leva consigo un alto prezo, aínda que saben que a súa riqueza é aproveitada polo Estado central. A última categoría prefire permanecer no Estado existente, xa que se trata dun segmento de poboación, con niveis educativos e ingresos altos, que é minoritario, pero que non ten as bases suficientes para formar un Estado propio. Se trasladamos o modelo de Horowitz á actualidade multiétnica de América Latina, atoparemos as seguintes variacións.

Horowitz ofrece o exemplo dos «Peles Vermellas de América» como os máis susceptibles de separarse como resposta ao alto grao de discriminación que sofren. Pero esta afirmación necesita importantes precisións para serlles aplicada

\footnotetext{
${ }^{6}$ A tradución é nosa.

7 «Red Indians of America», capítulo 4. Os indios dos Estados Unidos son tamén pobos orixinarios como no resto do continente.
} 
a nivel de xeneralidade aos pobos orixinarios, aínda que indíxenas de América Latina. Nestas terras aplícase moi ben a primeira categoría. En efecto, os grupos atrasados, na terminoloxía de Horowitz, son os indíxenas, que, en consecuencia, imprimiríanlle o atraso á rexión -sen entrar aínda na discusión da migración que contribuíu a que millóns de indíxenas radiquen en espazos urbanos. Tamén pode facerse extensiva a palabra rexión ao Estado-nación, o que significa que máis de catrocentos grupos identificables como indíxenas suman corenta millóns de persoas, desde pequenos grupos ata macroetnias, aimará, quechua na rexión andina, os maia e nahua en Mesoamérica -México, Guatemala, Honduras. En México hai dez millóns de indíxenas, pero representan entre o 12 e o $15 \%$ da poboación nacional. En Guatemala e Bolivia son a maioría e máis da metade en Perú e Ecuador. A Comisión Económia para América Latina (CEPAL) e o Banco Interamericano de Desarrollo (BID) calcularon que, malia que a poboación indíxena de América Latina abarca un 9\%, no mundo rural representa o 27\%. A pobreza dos pobos orixinarios é lacerante e está moi estendida. Guatemala, cun $90 \%$, e México, cun $80 \%$, encabezan a lista de indíxenas por debaixo da liña de pobreza, e despois veñen Perú, cun 79\%, e Bolivia, cun 75\%. Os indíxenas son grupos atrasados, en rexións atrasadas e no marco soberano de Estados-nación con niveis baixos de desenvolvemento.

A segunda categoría, os grupos avanzados en rexións atrasadas e/ou avanzadas, presenta un renovado vigor en América Latina a raíz dos rexurdimentos étnicos do discurso indianista de Evo Morales e a politización do pobo mapuche. Aínda que non é interese específico deste traballo -polo simple feito de que, sendo un grupo avanzado, non se axustaría ao noso argumento anterior sobre a pobreza da poboación orixinaria-, si que resulta útil mencionalo pola súa relevancia na reactivación do nacionalismo na rexión. Guayaquil, en Ecuador, e a Santa Cruz de la Sierra, en Bolivia, terían asignado o apelativo de grupo avanzado. Sen integrar poboacións indíxenas, antes ben, en oposición a elas, son os que, a través das súas organizacións e comités, enarboraron as propostas autonomistas máis desenvolvidas de América Latina. Os seus voceiros, ideoloxías e simpatizantes son abertos defensores da propiedade privada, da explotación dos recursos naturais e do mercado libre. Están afiliados a influentes sectores da Igrexa católica, teñen arraigamento nos valores e o civismo dos crioulos hispanos, aínda que recentemente a ideoloxía de Santa Cruz reivindica os 
indíxenas orixinarios das terras baixas de Bolivia. Argumentan que as súas rexións son as máis produtivas e as de maior comercialización cara ao exterior, e por iso lles fan fronte á inxustiza dun Estado e a unha burocracia centralista que absorbe a riqueza que as rexións producen. De aí que observaran nos modelos das comunidades autónomas do Estado español algunha inspiración para adaptar e introducir autonomía política e administrativa, normativa e fiscal, nos estatutos, institucións e parlamentos das súas rexións ${ }^{8}$.

Por último, a categoría de grupos atrasados en rexións avanzadas pode adaptarse á situación dos grupos indíxenas que emigran de distintas partes de México ás zonas de agricultura intensiva e asalariada dos estados de Baixa California e de Estados Unidos. Malia que varias xeracións de emigrantes indíxenas - mixtecos, mixes, zapotecos, triquis- se asentaron nas zonas de conurbación de cidades fronteirizas como Tijuana, Ensenada, Mexicali, e formaron organizacións para solucionar demandas de asentamento irregular, aínda non se atopan indicios de proxectos pola autonomía e o autogoberno, e moito menos movementos separatistas por parte do grupo de esta categoría-Organizaciones Indígenas de América Latina (ORGINDAL), Sector Norte Baixa California.

Da adaptación ao contexto latinoamericano do modelo de Horowitz desprendemos dúas consideracións importantes. En primeiro lugar, as condicións de pobreza e marxinación da vasta maioría dos pobos orixinarios -atrasados- adoitan ser impedimentos estruturais para presentar demandas autonomistas. En segundo lugar, os grupos avanzados, sen constituír maiorías dominantes, son os que introduciron propostas autonómicas máis completas.

Ata o de agora explicamos que os indíxenas non buscan un Estado propio, é dicir, a autodeterminación, senón unha autonomía que é o dereito á libre determinación. Malia o recoñecemento constitucional á libre determinación e á autonomía como un dereito integrado, para as poboacións orixinarias, nas constitucións da meirande parte dos Estados latinoamericanos, esta aínda adoita ser esporádica, limitada a casos paradigmáticos e, xa que logo, practicada ou tanxible de moi diversas formas. Por exemplo, en toda América Latina só o territorio de Kuna Ayala en Panamá lles foi concedido en forma semiautónoma aos kunas desde 1925; un goberno indíxena autónomo que tivo éxito baixo o modelo de democra-

\footnotetext{
${ }^{8}$ Acta de Guayaquil pola liberdade e autonomía rexional, Guayaquil, Ecuador, 15 de setembro de 2006.
} 
cia participativa é o da municipalidade de Cotacachi en Ecuador; en México, cento corenta municipios elixen as súas autoridades locais polo sistema de usos e costumes legalizados no Estado de Oaxaca; en Chiapas, os municipios autónomos declarados polo Ejército Zapatista de Liberación Nacional (EZLN), son entendidos como actos de rebeldía e desobediencia en contra do Estado. Así pois, hai unha diversidade de formas para exercer a autonomía proposta polos pobos orixinarios.

A autonomía dos grupos avanzados de Santa Cruz e, en menor medida, Guayaquil está escrita desde logo, con outra tinta, desde que esta provén, para protexer os intereses económicos, dunha elite empresarial, financeira e latifundista fronte aos campesiños sen terra e fronte á centralización do Estado boliviano e a estatalización dos recursos do gas e mais o petróleo. Así pois, podemos dicir, daquela, que os pobos orixinarios non teñen propostas secesionistas, como tampouco as teñen os grupos avanzados, malia que estes últimos inclúen propostas máis completas no aspecto fiscal e financeiro, como era de esperar (Urenda). Pero esta explicación sería moi parcial se non nos detemos agora a complementar o esquema de Horowitz co recurso metodolóxico do etnosimbolismo ou culturalismo histórico.

O teórico británico Anthony D. Smith encabeza desde 1984 a explicación do nacionalismo erixido sobre un poderoso etnocentrismo na forma de subxectividades tales como mitos, lendas e símbolos. Estas informacións proporcionan a autenticidade e mais a orixinalidade dunha etnia ou dunha nación. E son os vastos campos culturais sobre os que pode atoparse a lexitimación dun proxecto nacionalista ou etnonacionalista. $\mathrm{O}$ nacionalismo invoca as mitoloxías étnicas e resulta de pouca transcendencia argumentar se estas son inventadas, fabricadas ou son artificios ou recombinacións de elites ou intelectuais (Gutiérrez). $\mathrm{O}$ nacionalismo e mais a cultura son inseparables. Por medio dun proxecto político defende ou reivindica unha cultura que se percibe dominada, oprimida e que loita pola súa liberación -autonomía ou independencia- para expresarse. Este fenómeno, en alusión ao colonialismo interno, di Pablo González Casanova, repítese unha e outra vez -colonialismo interno, unha redefinición. Pero calquera nacionalismo só pode manifestarse cando existe primeiro unha conciencia -étnica, cultural, lingüística, territorial, relixiosa- e os seus vehículos de propagación -ideoloxías e proxectos-, así como os seus propios creadores -intelectuais, voceiros e ideólogos. 
Agora ben, América Latina vive hoxe un fascinante auxe do nacionalismo, cando menos nos seguintes temas: os rexurdimentos de aimarás, de maias, de quechuas, de mapuches e a fabricación de nacións recentes para lexitimar proxectos políticos que protexan os intereses de elites económicas; por exemplo, a nación camba das terras baixas bolivianas. Tamén sinalamos que outra faceta do nacionalismo actual latinoamericano é a exaltación e a utilización do pasado prehispánico e a identidade andina nos discursos de nacionalismo de Estado que acaban de poñer en práctica os gobernos de Bolivia, Venezuela e mais Ecuador. Os rexurdimentos de pobos orixinarios teñen características innovadoras porque son o resultado de proxectos postos en práctica polos indíxenas a través dos seus propios intelectuais e creadores e, xa que logo, están encamiñados a fortalecer, facer visible ou recuperar as identidades indíxenas sumamente desgastadas polos efectos hostís e discriminatorios das nacións dominantes dos nacionalismos de Estado.

$\mathrm{Na}$ actualidade, a tecnoloxía da información está a axudar, como nunca antes, a que sexamos testemuñas dun auxe das culturas, linguas e expresións literarias, entre moitas outras, que están a levar a cabo os pobos orixinarios en resposta, oposición ou desafío ao nacionalismo de Estado. Unha resposta defensiva e estruturada fronte ao nacionalismo de Estado, pero de contido étnico actual -por exemplo o nacionalismo aimará de Bolivia-, é o que enarbora o autodenominado «nacionalismo cruceño» e a nación camba en Sudamérica. De feito, é o único movemento non oficial que utiliza explicitamente o nacionalismo como instrumento político e como acto de resistencia cívica fronte á defensa de intereses económicos e petroleiros. Podería dicirse que a posición da nación camba é de grande interese para o analista dos estudos de nacionalismo. Isto é así porque se trata dunha nación inventada, que ten todos os atributos míticos e lendarios, é dicir, unha historia específica do descubrimento dun territorio e da fundación dunha cidade, dunha mestizaxe biolóxica indíxena e crioula, e dunha cultura camba mestiza que se beneficiou das inmigracións do século XX provenientes de árabes, alemáns, italianos, croatas e paraguaios crioulos. Esta invención mítica de douscentos anos é o resultado, tanto imaxinado como estudado, dos seus ideólogos e intelectuais ao servizo da manutención dunha nación camba, que por autopercepción se identifica como de raza branca e que se atopa en aberta competencia e discrepancia co sistema andino colla da por eles chamada Bolivia do Alto Perú, que fomenta un andinocentrismo que inhibe a plurinacionalidade da 
que se sente parte a devandita nación camba. En suma, en América Latina albíscanse dous proxectos políticos con forte carga étnica, por unha banda, o rexurdimento aimará, que é fundamental para entender o nacionalismo oficial da Bolivia de hoxe, e pola outra, a invención dunha nación para lexitimar o proxecto político e os intereses económicos dun grupo avanzado. Desas dúas proposicións pode desprenderse que a partir dun rexurdimento étnico, ou invención, se ofrece a posibilidade dunha autonomía de onde pode nacer ou non un nacionalismo que teña como obxectivo a independencia ou o Estado propio.

Mentres os pobos orixinarios non reivindiquen os seus nomes propios e continúen a aglutinarse nunha loita discursiva e amorfa de movemento indíxena, é dicir, sen identificar a multiplicidade e o antagonismo entre actores, elites, ideoloxías, formas de organización, por mencionar só algúns, os prospectos estarán aínda máis limitados para especular coa separación. Do que xustamente os indíxenas de todos os grupos étnicos carecen é dun acceso ao Estado e, aínda máis, non propuxeron estratexias estruturais e ideolóxicas para ter un propio.

Cando os indios recuperan o seu propio discurso unido a un pasado mitolóxico, real ou inventado, segue a causar gran temor e suspicacia nos sectores non indíxenas. No contexto desta incomprensión xorden as condicións propicias para etiquetar as demandas lexítimas de mobilizacións e organizacións indíxenas fronte á defensa dos seus territorios e recursos naturais no novo fenómeno coñecido como a criminalización das demandas sociais impulsadas tanto por gobernos progresistas, socialistas ou da dereita. Por exemplo, no goberno de Michelle Bachelet e a aplicación da lei antiterrorista aos mapuches e a condena por defender os seus territorios e a súa cultura ante os intereses transnacionais. En México, os gobernos do Partido Acción Nacional (PAN), co despregamento dunha cobertura favorable dos medios, mostraron unha inusitada intolerancia fronte ás mobilizacións en defensa de dereitos laborais e ambientais, que culminaron co arresto e encarceramento dos principais dirixentes.

\section{CONFLITO ÉTNICO E SOCIOLOXÍA DOS DESASTRES}

Calquera conflito aparece no momento en que hai conciencia sobre a ocupación ou a necesidade de recuperar o que historicamente lles pertence: terras, patrimo- 
nio, recursos naturais, cultura, lingua. É étnico cando as poboacións con características distintas de identidade con base na lingua, a historia ou a cultura presentan unha acción colectiva para recuperar, defender ou conservar algo. A estratexia de mobilización pode ser cara a outros suxeitos: Estado, transnacionais ou privados. Os conflitos non son accidentes nin resultan circunstanciais, senón que se van incubando, de aí a utilidade de aplicar o modelo da socioloxía do risco.

O conflito étnico de América Latina está enmarcado en distintos tipos de violencia que, aínda que non a grande escala ou expresada en enfrontamentos polarizados entre unha ou máis etnias, si resulta moi frecuente e reiterada.

A socioloxía dos desastres elaborou o concepto de risco como un suceso inherente á sociedade moderna (Giddens, 1990; Luhmann, 1993). Os riscos máis estudados son aqueles derivados do manexo humano, na industria e os que proceden do impacto xerado polos desastres naturais ou os riscos ambientais. $\mathrm{O}$ noso traballo quere tomar como modelo a socioloxía dos desastres para enmarcar como acontece a construción do risco cando están involucrados os aspectos étnicos.

O fenómeno étnico fai referencia a unha construción que sinala fronteiras simbólicas e subxectivas que posibilitan diferenzas de orde cultural, relixiosa ou linguiística. A poboación orixinaria -autóctona- é tipificada como "étnica» en virtude da conservación e socialización endóxena dalgunhas das diferenzas mencionadas que lles confiren aos membros que se identifican sentido de adscrición e pertenza. Esa poboación mantén un sistema de relacións sociopolíticas e económicas desiguais, que a sitúan en subordinación con respecto ao grupo étnico ou cultural dominante da nación; por exemplo, o mestizo. Así, un conflito étnico defínese pola acción política organizada dos que se identifican con intereses étnicos, de maneira que o conflito tampouco é unha obra espontánea ou froito da casualidade (Stavenhagen, 2000).

A nosa análise trata de explicar por que a etnicidade é máis propensa a situacións de desastre, non só de tipo natural -ciclóns, furacáns-, senón pola inxerencia instrumental dun manexo humano que actúa sen sanción estatal, baixo a súa aprobación, ou na indiferenza. $\mathrm{O}$ dano acontece pola propia ineficacia da burocracia, a falta de coordinación, protección e coherencia institucional. A inxerencia do Estado, en calquera sentido, quer como executor directo, quer por complicidade, posibilita a construción dun risco e non actúa para evitar ou sequera controlar o seu desencadeamento. 
O estudo do risco é unha preocupación da sociedade moderna (Giddens, 1993; Beck, 1992; Luhmann, 1993). É unha forma de racionalidade que tenta explicar os perigos ou ameazas que implican perdas humanas ou materiais, pero tamén se ocupa da prevención, para mitigar o impacto do dano. Cos autores sinalados, convimos en que calquera risco supón unha construción social, é dicir, non existen nin a fatalidade nin o destino, a maxia ou o castigo divino; é no manexo humano -de aí a súa racionalidade- onde se localizan as causas do acontecido ou a magnitude do dano.

A socioloxía dos desastres contribuíu á teorización do risco en diversos contextos ambientais, ecolóxicos e/ou industriais. Dese vasto campo de investigación e análise resulta posible adecuar conceptos e modelos para explicar como se constrúe unha situación de risco nunha zona socialmente conflitiva e onde acontece un dano de graves magnitudes. Se entendemos que ningún risco é obra da casualidade, podemos, daquela, afirmar que tamén é posible construír un escenario de risco provocado por diversos e antagónicos intereses colectivos que deriven en violencia. Nun esquema típico da socioloxía do desastre habería que explicar o erro humano que provoca unha explosión nunha planta industrial, como se pode previr un furacán, evitar unha contaminación de auga ou controlar unha epidemia. A causa de todos estes fenómenos na sociedade moderna non se pode explicar, como xa dixemos, pola fatalidade. Pola súa magnitude e inxerencia pública e impacto social, así como polo desenvolvemento tecnolóxico de que se dispón, tampouco se poden reducir a meros accidentes. Así, daquela, atopamos unha grande utilidade na socioloxía do desastre para explicar e comprender as causas que motivan a violencia a grande escala, de maneira frecuente e, o que resulta moi importante, que prexudican, aínda máis, unha poboación con histórica vulnerabilidade.

Un risco, segundo a definición de Lupton, é un fenómeno obxectivo, non estático e constantemente construído e negociado como parte dunha rede de interaccións sociais e de significado. Un risco, xa que logo, é unha engrenaxe de significados, lóxicas e crenzas que gravitan e interfiren na forma de observar e interpretar os fenómenos materiais -desde explosións e furacáns, ata masacres. Pola súa evidencia obxectiva e pola variedade de significados, o risco ten un peso simbólico e político de especial consideración. Desde esta perspectiva, o enfoque cultural e simbólico de Douglas resalta o uso político do risco, xa que do seu 
impacto se derivan importantes cargas de culpabilidade, responsabilidade e rendición de contas - accountability- que lle dan dimensión e profundidade social ao dano producido.

Como o feito de que acontezan un risco e un dano é debido ás decisións, ou á falta delas, tomadas por un ou varios actores, non se pode illar da esfera política. É congruente, xa que logo, que nas sociedades modernas, segundo Giddens e Beck, os riscos respondan a unha lóxica e a un cálculo, por exemplo, certas contaminacións sobre recursos naturais ou estragos ambientais son responsabilidade humana. A intervención e decisión dos actores supón a realización de cálculos e a existencia dunha planificación para evitar ou contrarrestar os efectos perniciosos e destrutores para a poboación e o seu contorno. Tal como acontece no sistema básico de saúde, a prevención é preferible á corrección de consecuencias que quedaran fóra de control. Fronte á identificación dun risco, o Estado de benestar intervén para mitigar, evitar ou diminuír o dano, a ameaza ou o perigo e, xa que logo, para previr e protexer a poboación que pode ser afectada.

Así pois, a responsabilidade principal do Estado que posibilita, ou cando menos non evita, un clima de terror continuo ou danos frecuentes entre as poboacións indíxenas é unha parte fundamental do modelo do risco e o conflito étnico. Ante unha gradual sucesión de acontecementos que apuntan cara a múltiples riscos que poden detonar en tráxicos desastres entre a poboación civil, incluída a indíxena, o Estado pouco fai por evitalos. Que o Estado dea lugar ou tolere que acontezan situacións que desencadeen en violencia, que intente ou permita a desaparición física de civís, que lles dea privilexios e garantías aos intereses de transnacionais, que evite a súa responsabilidade na contaminación ambiental e a deterioración climática, que favoreza plans que teñen que ver coa saúde e o medio natural polo combate ao narcotráfico, pode ser debido a moitas causas, entre as que se atopan a pobreza, a escaseza ou a loita polos recursos, a falta de coordinación entre as institucións, a presión internacional, o illamento xeográfico, entre outras. Calquera que sexa a resposta, o asunto é que o saldo da ineficacia burocrática cobra un maior número de vítimas entre os máis vulnerables, os indíxenas. Os danos sufridos polos indíxenas como consecuencia dunha construción de risco son o resultado dun exterminio e/ou destrución física, un atentado permanente ás súas formas de vida e supervivencia. 